\title{
Evaluation of cytotoxicity and mechanism of apoptosis of doxorubicin using folate-decorated chitosan nanoparticles for targeted delivery to retinoblastoma
}

\author{
Suphiya Parveen $\cdot$ Sanjeeb K. Sahoo
}

Received: 2 August 2010 / Accepted: 21 October 2010 /Published online: 25 October 2010

(C) Springer-Verlag 2010

\begin{abstract}
Nanoparticles are the new entities that can greatly limit the various side effects of systemic chemotherapy, and that coupled with a targeting moiety enables site-specific delivery of drugs. Folate receptors are overexpressed in retinoblastoma cells, thus these can specifically uptake the drug-loaded nanoparticles, thereby increasing the cytotoxicity at the tumor site. In our work, doxorubicin-loaded chitosan nanoparticles was prepared and then conjugated to folic acid. The conjugation efficiency was characterized by nuclear magnetic resonance and Fourier transform infrared spectroscopy. Thereafter, the efficacy of FA-conjugated DOX-CNPs on retinoblastoma cells (Y-79) was analyzed by MTT assay which demonstrated superior cytotoxic effects as compared to unconjugated DOX-CNPs and native DOX. This may be due to enhanced intracellular uptake of DOX-CNPs-FA $(30 \%)$ than that of DOX-CNPs (13.24\%) and native DOX (5.01\%), resulting from the high affinity of FA for folate receptors. Finally, the mechanism of doxorubicin-mediated apoptosis in retinoblastoma cell line (Y-79) was investigated which demonstrated that the mitochondrial pathway is activated and that the FA-conjugated DOX-CNPs are most effective and causes enhanced release of cytochrome $c$ as well as the activation of downstream caspases to assist in apoptosis. Thus, the FA-targeted NPs were proved to possess sustainable, controlled, and targeted delivery of anticancer drugs with DOX as a model drug, which may provide a drug delivery system of precise control and targeting effect for the treatment of retinoblastoma.
\end{abstract}

S. Parveen $\cdot$ S. K. Sahoo $(\square)$

Laboratory of Nanomedicine, Institute of Life Sciences,

Nalco Square, Chandrasekharpur,

Bhubaneswar, Orissa, India

e-mail: sanjeebsahoo2005@gmail.com
Keywords Nanoparticles · Chitosan · Folic acid · Doxorubicin $\cdot$ Retinoblastoma $\cdot$ Targeted drug delivery

\section{Introduction}

Cancer is a debilitating disease that causes millions of death each year. Though chemotherapeutics do exist to combat cancer, one of the most serious issues is the nonselective nature of the chemotherapeutic drugs, which causes innumerable side effects (Parveen and Sahoo 2008). Thus, realizing the importance of targeted drug delivery specifically to the site of action is the need of the hour. Retinoblastoma is one such cancer that causes serious malignant intraocular tumor in infants and children and often results in loss of vision and secondary malignancies (Abramson 1990; Smith and Donaldson 1991). Recent treatment options for retinoblastoma include external beam radiotherapy, episcleral plaque radiotherapy, and cryotherapy (Amendola et al. 1989), but these are frequently associated with complications, such as facial deformities, cataract, radiation retinopathy, and a substantial risk of secondary tumors (Abramson and Frank 1998). Systemic chemotherapy is also limited by toxicity, rapid blood clearance, and multi-drug resistance (Chan et al. 1989). Moreover, ocular drug delivery is also impaired due to the natural defensive barriers of the retina that protect the eye. Thus, targeting it in a safe and effecting manner would be helpful to the majority of children diagnosed with retinoblastoma, especially in developing countries where the probability of survival is closer to $50 \%$ due to poor education, lower socioeconomic status and inadequate healthcare systems, which results in delayed diagnosis and suboptimal care (Rodriguez-Galindo et al. 2008). 
Nanoparticles (NPs) are promising entities that can greatly reduce the problems due to drug delivery and retention. These are submicron-sized polymeric colloidal particles, with diameters ranging from 10 to $1,000 \mathrm{~nm}$, in which the therapeutic agent of interest can be encapsulated within the polymeric matrix or adsorbed or conjugated onto the surface (Parveen and Sahoo 2008; Sahoo and Labhasetwar 2003; Sahoo et al. 2007). Chitosan nanoparticles (CNPs) are especially suitable for ocular drug delivery due to their mucoadhesiveness and ability to cross the tight epithelial junctions, thus increasing the residence time of the drug (Calvo et al. 1997b; de Campos et al. 2001; Genta et al. 1997). Moreover, these NPs can be surface functionalized by specific ligands to achieve targeted drug delivery to the tumor site, thus improving the therapeutic efficacy and reducing the side effects of chemotherapy. Several studies have shown that folic acid (FA) is an attractive targeting moiety for cancer therapy due to its high affinity for folate receptors $\left(K_{\mathrm{d}} \sim\right.$ $10^{-10} \mathrm{M}$; Leamon and Reddy 2004; Lu and Low 2003; Lu et al. 2004). Folate receptors are overexpressed in the membrane of many human cancer cells such as brain, kidney, breast, lung, retinoblastoma, etc. (Kansara et al. 2008; Saul et al. 2003; Sudimack and Lee 2000) and the expression level of folate receptor in tumors is around 100-300 times higher than in normal tissues (Ross et al. 1994). Thus, because of this distinguishing property, FA has emerged as an appropriate targeting ligand and can be exploited in designing a suitable convey system that can specifically deliver the drug pay load at the therapeutic site.

In this study, we evaluated the therapeutic effects of folatedecorated chitosan nanoparticles (CNPs-FA) for targeted delivery of hydrophilic anticancer drugs with doxorubicin (DOX), chosen as the model drug, as it is widely used chemotherapeutic drug for the treatment of retinoblastoma (Serpe et al. 2006). The drug-loaded CNPs (DOX-CNPs) were prepared and decorated with folic acid (DOX-CNPsFA), which was then characterized by various analytical techniques such as laser light scattering for particle's size, zeta potential analyzer for surface charge, and nuclear magnetic resonance (NMR) and Fourier transform infrared spectroscopy (FTIR) for surface chemistry. Thereafter, comparative analysis of intracellular uptake of drug and drug-loaded CNPs (conjugated and unconjugated nanoparticles) on retinoblastoma cells (Y-79) was carried out to access the specificity of the folate receptors and to ascertain whether nanoparticles are taken up more than the native drug. The therapeutic effect of doxorubicin formulated in the CNPs (with folate targeting effect) was also evaluated in vitro by measuring the viability and the extent of apoptosis of human retinoblastoma cells (Y-79). Furthermore, the DOXmediated apoptotic pathway was investigated wherein the effects of various formulations on the kinetics of cytochrome $c$ release, mitochondrial membrane potential, and activation of various downstream caspases were analyzed by western blotting.

\section{Materials and methods}

\subsection{Materials}

Chitosan $(60-90 \mathrm{kDa}$, degree of deacetylation $=85 \%$, derived from crab shells, in the form of fibrillar flakes), sodium triphosphate pentabasic (TPP), doxorubicin, folic acid, sodium chloride, disodium hydrogen phosphate, and potassium chloride were obtained from Sigma-Aldrich Co. (St Louis, MO, USA). Propidium iodide (PI) was obtained from Invitrogen (Leiden, The Netherlands). Potassium hydrogen phosphate and dimethyl sulfoxide were purchased from Qualigens Fine Chemicals, Mumbai. Acetonitrile was purchased from E-merk, India. Ultrapure water (Millipore, Bedford, MA, USA) was used throughout. All other chemicals were of analytical grade unless where otherwise stated.

\subsection{Preparation of doxorubicin-loaded chitosan nanoparticles}

Doxorubicin-loaded CNPs were prepared by a modified ionic gelation method as reported by Calvo et al. (1997a, b). Briefly, $2 \mathrm{ml}$ of an aqueous solution of TPP $(2.91 \mathrm{mg} /$ $\mathrm{ml}$ ) was slowly added drop wise into $10 \mathrm{ml}$ of chitosan solution $(1.75 \mathrm{mg} / \mathrm{ml}, \mathrm{pH}=5)$ containing DOX $(5.25 \mathrm{mg})$. After overnight stirring, the CNPs were collected by centrifugation (SIGMA 3K30, Germany) at 18,000 rpm for $30 \mathrm{~min}$ at $4^{\circ} \mathrm{C}$. The pellets were then dispersed in double distilled water and lyophilized (LYPHLOCK, Labconco, MO) for $48 \mathrm{~h}$ and then stored at $4^{\circ} \mathrm{C}$ for further studies.

2.3 Nanoparticle surface modification: synthesis of folate CNPs

Folate-conjugated CNPs were synthesized by coupling the freeze-dried CNPs to an activated folic acid as described in previous studies with minor modifications (Guo et al. 2000; Lee and Low 1995). Briefly, $5 \mathrm{mg}$ of the freeze-dried CNPs dissolved in $5 \mathrm{ml}$ of DMSO were mixed with $1.3 \mathrm{mg}$ of folic acid and $1.3 \mathrm{mg}$ of DCC. The reaction was performed at room temperature for $7 \mathrm{~h}$ and then mixed with $50 \mathrm{ml}$ of distilled water and centrifuged at 3,000 rpm. The pellet was then dialyzed and dried to obtain CNPs-FA. The formation of folate-conjugated CNPs was monitored and confirmed by analyzing the concentration of conjugated folic acid in a 
known amount of the sample at $365 \mathrm{~nm}$ by a UV-Visible spectrophotometer (Synergy HT, BioTek ${ }^{\circledR}$ Instruments Inc., Winooski, VT; Yoo and Park 2004). Serially diluted concentrations of folic acid in DMSO were used to construct a calibration curve.

\subsection{Characterization of doxorubicin-loaded CNPs with folate decoration}

\subsubsection{Particle size analysis and zeta potential measurement}

Mean particle size and size distribution of the nanoparticles was determined by photon correlation spectroscopy (PCS) and laser Doppler anemometry, respectively, using a Zetasizer (Nano ZS, Malvern Instruments, UK), with a red laser of wavelength $\lambda_{\mathrm{o}}=633 \mathrm{~nm}(\mathrm{He}-\mathrm{Ne}, 4.0 \mathrm{Mw})$. PCS makes it possible to calculate the average diffusion coefficient $(D)$ of the particles. Assuming that the particles are solid, the mean diameter $(d)$ can be easily calculated by the Stokes-Einstein (Finsy 1994).

$d=\frac{K t}{3 \lambda \eta D}$

Where $k$ is the Boltzman constant, $T$ is the absolute temperature, and $\eta$ is the viscosity of the medium. For size measurements, $\sim 1 \mathrm{mg}$ of CNPs was dissolved in $1 \mathrm{ml}$ of water which was further diluted with water and measured for a minimum of $120 \mathrm{~s}$. Zeta potential measurements were made similarly with $\sim 1 \mathrm{mg}$ of CNPs dissolved in $1 \mathrm{ml}$ of water which was further diluted and placed in an electrophoretic cell, where a potential of $\pm 150 \mathrm{mV}$ was established. All the samples were maintained at a constant temperature of $25.0 \pm 0.1^{\circ} \mathrm{C}$ in all experiments, and each batch was analyzed in triplicates.

\subsubsection{Transmission electron microscopic studies}

Particle morphology was examined by transmission electron microscopy (TEM, Philips CM-10, FEI Inc., Hillsboro, OR, USA). Samples (nanoparticulate suspensions, $100 \mu \mathrm{g} / \mathrm{ml}$ ) were dropped into Formvar-coated copper grids, and after complete drying, the samples were stained using $2 \% w / v$ uranyl acetate (Electron Microscopy Services, Ft. Washington, PA). Image capture and analysis were done using Digital Micrograph and Soft Imaging Viewer Software.

\subsubsection{Surface morphology}

Scanning electron microscopy The surface morphology of CNPs was studied by scanning electron microscopy (SEM). For this, CNPs were sputtered with gold to make them conductive and placed on a copper stub. The images were taken using scanning electron microscope (JSM-T220A, JEOL, MA).

Atomic force microscopy The surface properties of the formulated CNPs were observed by an atomic force microscopy (NanoScope III A, Veeco, USA). Explorer atomic force microscope was a tapping mode, using high resonance frequency $\left(F_{\mathrm{o}}=312 \mathrm{kHz}\right)$, pyramidal cantilevers with silicon probes having force constants of $20 \mathrm{~N} / \mathrm{m}$. Scan speed was set at $2 \mathrm{~Hz}$. The samples were dissolved in PBS $(0.1 \mathrm{M}, \mathrm{pH} 7.4)$ and then dropped on freshly cleaved mica plates, followed by vacuum drying for $24 \mathrm{~h}$ at $25^{\circ} \mathrm{C}$.

\subsubsection{Surface chemistry}

Nuclear magnetic resonance The decoration of FA on the surface of doxorubicin-loaded CNPs was confirmed by NMR. The NMR spectra was recorded on a spectrometer (FT NMR Spectrometer, JEOL, $400 \mathrm{MHz}$, Japan) at room temperature using DMSO as a solvent (Wan et al. 2008).

Fourier transform infrared spectroscopy The FTIR transmission spectrum of various samples (folic acid, DOX, and DOX-CNPs-FA) was obtained from SPECTRUM RX I (Perkin Elmer, FTIR Spectrometer, USA). A total of 2\% ( $w /$ $w)$ of sample, with respect to potassium bromide $(\mathrm{KBr})$, was mixed with dry $\mathrm{KBr}$, and the mixture was ground into fine powder using an agate mortar before compressing into $\mathrm{KBr}$ disc under a hydraulic press at 10,000 psi. Each $\mathrm{KBr}$ disc was then scanned at $4 \mathrm{~mm} / \mathrm{s}$ at a resolution of $2 \mathrm{~cm}^{-1}$ over a wave number region of $400-4,000 \mathrm{~cm}^{-1}$ using IR solution software (ver.1.10), and the characteristic peaks for different samples were recorded.

\subsubsection{Drug encapsulation efficiency}

The encapsulation efficiency (EE\%) was determined by the separation of nanoparticles from the aqueous medium containing non-associated doxorubicin by centrifugation of the samples at $18,000 \mathrm{rpm}$ for $30 \mathrm{~min}$ at $4^{\circ} \mathrm{C}$ (SIGMA 1$15 \mathrm{~K}$, Germany). The supernatant was used to estimate the drug concentration which was not encapsulated in the NPs by fluorescence spectrophotometer (Synergy HT, BioTek ${ }^{\circledR}$ Instruments Inc., Winooski, VT) at $\lambda_{\text {ex }}=485 \mathrm{~nm}$ and $\lambda_{\mathrm{em}}=$ $591 \mathrm{~nm}$ (Misra and Sahoo 2010). Doxorubicin solutions of various concentrations were prepared and similarly quantified to generate a calibration curve for the EE calculations for the doxorubicin-loaded CNPs. Triplicate samples (supernatants) were analyzed, and the doxorubicin encapsulation efficiency was calculated by dividing the amount 
of doxorubicin entrapped by the total amount of doxorubicin added, multiplied by 100 .

\subsection{In vitro release kinetics}

Freeze-dried CNPs ( $\sim 5 \mathrm{mg})$ were resuspended in $1 \mathrm{ml}$ of phosphate-buffered saline solution (PBS, $\mathrm{pH}$ 7.4) and incubated at $37^{\circ} \mathrm{C}$ under light agitation of $150 \mathrm{rpm}$ using an incubator shaker (Wadegati Labequip, India; $n=3$ ). At appropriate time intervals, individual samples were collected by centrifugation (SIGMA $3 \mathrm{~K} 30$, Germany) at $18,000 \mathrm{rpm}$ for $10 \mathrm{~min}$, and the amount of the drug in the release medium was determined by fluorescence spectrophotometer (Synergy HT, BioTek ${ }^{\circledR}$ Instruments Inc., Winooski, VT) at $\lambda_{\mathrm{ex}}=485 \mathrm{~nm}$ and $\lambda_{\mathrm{em}}=591 \mathrm{~nm}$ (Misra and Sahoo 2010). Calibration curves were made with the incubation medium, and all measurements were performed in triplicates.

\subsection{Cell culture}

Human retinoblastoma cell line (Y-79) was obtained from the American Type Culture Collection (ATCC, Manassas, VA) and were cultured in RPMI 1640 with $10 \%$ fetal bovine serum and $1 \%$ penicillin-streptomycin at $37^{\circ} \mathrm{C}$ in a humidified 95\% air $/ 5 \% \mathrm{CO}_{2}$ incubator (Hera Cell, Thermo Scientific, Waltham, MA). All reagents for cell culture were obtained from Himedia Laboratories Pvt. Ltd., Mumbai, India.

\subsection{Assessment of cytotoxicity}

The antiproliferative activity of doxorubicin was analyzed by the 3-(4, 5-dimethylthiazol-2-yl)-2, 5-diphenyl tetrazolium bromide (MTT)-based colorimetric assay (Mosmann 1983). The MTT assay is a quantitative and rapid colorimetric method, based on the cleavage of a yellow tetrazolium salt to insoluble purple formazan crystals by the mitochondrial dehydrogenase of viable cells (Al-Joudi et al. 2005). The MTT assay was carried out according to a previously reported procedure (Sahoo and Labhasetwar 2005). Y-79 cells were seeded at 5,000 per well density in 96 well plates (Corning, NY, USA), and after $24 \mathrm{~h}$, drug either as a solution or encapsulated in nanoparticles at different concentrations $(0.1-100 \mu \mathrm{M} / \mathrm{ml})$ was added to separate wells. Medium and void nanoparticles (without drug) served as respective controls. Medium was changed on day 2 after the treatment and then every alternate day, and no further dose of the drug was added. After the specified incubation time (5 days), $10 \mu \mathrm{l}$ MTT (Sigma) was added, and the plates were incubated for $3 \mathrm{~h}$ at $37^{\circ} \mathrm{C}$ in a cell culture incubator (Hera Cell, Thermo Scientific, Waltham, MA), following which the intracellular formazan crystals were solubilized in dimethyl sulfoxide and the color intensity measured at $540 \mathrm{~nm}$ using a microplate reader (Synergy HT, BioTek Instruments, Inc., Winooski, VT). The antiproliferative effect of different treatments was calculated as a percentage of cell growth with respect to respective controls.

\subsection{Assessment of apoptosis by flow cytometry}

Annexin V-FITC staining was used for the assessment of apoptosis. This assay is based on the observation that soon after the initiation of apoptosis, phosphotidylserine (PS) translocates from the inner face of the plasma membrane to the cell surface. The translocated PS can thus be easily detected by staining with a FITC conjugate of Annexin V, a protein that has a strong natural affinity for PS (Koopman et al. 1994). The induction of apoptosis by DOX, DOX-CNPs, and DOX-CNPs-FA was studied by flow cytometry. In $25 \mathrm{~cm}^{2}$ culture flasks (Corning, NY, USA), $1 \times 10^{5}$ cells $/ \mathrm{ml}$ were grown overnight, after which $5 \mu \mathrm{M} / \mathrm{ml}$ concentration of free DOX and equivalent concentration of various formulations of DOX-loaded CNPs were added to the flasks, and the cells were incubated for $48 \mathrm{~h}$ in $\mathrm{CO}_{2}$ incubator (Hera Cell, Thermo Scientific, Waltham, MA). After the specified incubation periods, the cells were washed thrice with PBS (0.1 M, pH 7.4) and then resuspended in $100 \mu \mathrm{l}$ of $1 \times$ binding buffer (Clontech Laboratories, Inc., Palo Alto, CA). Thereafter, $5 \mu$ l Annexin V-FITC (final concentration, $1 \mu \mathrm{g}$ / $\mathrm{ml}$; BD Biosciences Pharmingen) and $5 \mu \mathrm{l}$ propidium iodide (10 $\mu \mathrm{g} / \mu \mathrm{l}$; MP Biomedicals, Inc., Germany) were added to the cells and incubated at room temperature in dark for $20 \mathrm{~min}$. Before flow cytometric analysis, $400 \mu \mathrm{l}$ of $1 \times$ binding buffer were added to the cells and the extent of apoptosis was determined by analyzing 15,000 ungated cells using a FACScan flow cytometer and Cell Quest software (FACSCalibur; Becton-Dickinson, San Jose, CA).

\subsection{Cell cycle distribution analysis by flow cytometry}

The effects of CNPs on cell cycle progression and population distribution were determined by flow cytometry. Y-79 cells were seeded at $1 \times 10^{5}$ cells $/ \mathrm{ml}$ in $75-\mathrm{cm}^{2}$ flask (Corning, NY, USA), and it was treated with $5 \mu \mathrm{M} / \mathrm{ml}$ of DOX, DOX-CNPs, and DOX-CNPs-FA. Doxorubicininduced cell cycle arrest was detected by comparing the cell cycle profiles between doxorubicin-treated cells and CNP-treated cells with that of the control cells. Forty-eight hours posttreatment, the cells were collected by centrifugation, washed thrice with $\mathrm{PBS}(0.1 \mathrm{M}, \mathrm{pH} 7.4)$ to remove any uninternalized CNPs or the native doxorubicin, and thereafter, cells were incubated in propidium iodide $(20 \mu \mathrm{g} /$ $\mathrm{ml}$ ) for $30 \mathrm{~min}$. The DNA content was measured for 15,000 events for each sample (FACS Caliber instrument; Becton, 
Dickinson \& Co, Franklin Lakes, NJ). Data were plotted using CellQuest software (Becton, Dickinson \& Co).

\subsection{Assessment of cellular uptake}

Twenty-four well plates (Corning, NY, USA) were seeded with Y-79 cells at $5 \times 10^{4}$ cells per well density and $24 \mathrm{~h}$ post-seeding, the medium in each well was replaced with $1 \mathrm{ml}$ of freshly prepared suspension of DOX-CNPs and DOX-CNPs-FA in medium $(300 \mu \mathrm{g} /$ well $)$, and the plates were incubated for $2 \mathrm{~h}$ as described earlier in our previous paper (Parveen et al. 2010). An equivalent concentration of doxorubicin was also added to the cells.

For folic acid competition experiments, the cells were cultured overnight with $0-3 \mathrm{mM}$ folic acid prior to the addition of the particles. The experiment was terminated after $2 \mathrm{~h}$ by washing the cell monolayer thrice with ice-cold PBS, $0.1 \mathrm{M}, \mathrm{pH}$ 7.4, and lysing the cells by incubating with $0.1 \mathrm{ml}$ of $1 \times$ cell lysis buffer (Promega, Madison, WI) for $30 \mathrm{~min}$ at $37^{\circ} \mathrm{C}$. The cells were washed thrice and resuspended in PBS (0.1 M, pH 7.4). The amount of endocytosed particles inside cells was analyzed by FacsCalibur flow cytometry. The mean fluorescence intensity (MFI) of the cells at FITC-A was measured.

\subsection{Confocal laser scanning microscopic studies}

To study the intracellular retention of the drug, Y-79 cells were seeded in Bioptechs plates (Bioptechs, Butler, PA) at $5 \times 10^{4}$ cells per plate in $1 \mathrm{ml}$ of growth medium $24 \mathrm{~h}$ prior to the experiment. Thereafter, cells were treated with $5 \mu \mathrm{M} /$ $\mathrm{ml}$ of either the native drug, DOX in solution, or DOXloaded CNPs (DOX-CNPs and DOX-CNPs-FA). Untreated cells were used as control to account for the autofluorescence, if any. The medium was changed on day 2 after the treatment and then every alternate day, and no further dose of DOX was added. At different time points, the cells were washed thrice with PBS $(0.1 \mathrm{M}, \mathrm{pH}$ 7.4) to remove any uninternalized drug/CNPs and then visualized using a confocal microscope (Leica TCS SP5, Leica Microsystems $\mathrm{GmbH}$, Germany) that is equipped with an argon laser with an excitation wavelength set at $488 \mathrm{~nm}$ and emission at $590 \mathrm{~nm}$ (Janes et al. 2001). Detection was with a band-pass emission barrier filter. The images were processed using Leica Application Suite software.

\subsection{Mitochondrial transmembrane potential}

The mitochondrial membrane potential changes were analyzed by flow cytometry using a mitochondriaselective dye JC-1 (5,5',6,6'-tetrachloro-1,1',3,3'-tetraethylbenzimidazolcarbocyanine; Sigma-Aldrich Chemicals, Germany) (Rees et al. 1991; White and Reynolds 1996).
JC-1 is a lipophilic cation, which in normal polarized mitochondria exists as aggregates. Depolarization due to loss of mitochondrial membrane potential causes the aggregates to dissolute into the monomeric forms. Thus, JC-1 forms either J-aggregates or monomers, depending on the state of the mitochondrial membrane potential, with the missions of the two dye forms detectable by flow cytometry at 585 (FL2) or $530 \mathrm{~nm}$ (FL1), respectively (Cossarizza et al. 1993). For the JC-1 analysis, cells $(2 \times$ $10^{5}$ ) were treated with $5 \mu \mathrm{M} / \mathrm{ml}$ of native DOX, DOXCNPs, and DOX-CNPs-FA for $48 \mathrm{~h}$ at $37^{\circ} \mathrm{C}$. Thereafter, the cells were collected by centrifugation, washed thrice with PBS (0.1 M, pH 7.4) to remove any uninternalized CNPs or the native doxorubicin, and thereafter, cells were stained with $\mathrm{JC}-1$ for $15 \mathrm{~min}$ at $37^{\circ} \mathrm{C}$, washed thrice with PBS (0.1 M, pH 7.4), and analyzed for changes in membrane potential by FACScan flow cytometer and Cell Quest software (FACSCalibur; Becton-Dickinson, San Jose, CA). All experiments were performed in triplicates.

2.13 Determination of cytochrome $c$ release by western blot analysis

Cytosolic and mitochondrial fractions were analyzed for cytochrome $c$ content by immunoblotting. Briefly, Y-79 cells $\left(1 \times 10^{6}\right)$ were treated with $5 \mu \mathrm{M} / \mathrm{ml}$ of native DOX, DOX-CNPs, and DOX-CNPs-FA for different time intervals $(2,24$, and $48 \mathrm{~h})$ at $37^{\circ} \mathrm{C}$. Thereafter, cells were harvested and washed thrice with cold PBS $(0.1 \mathrm{M}, \mathrm{pH} 7.4)$ and sedimented by centrifugation. Cell fractionization was performed as described by the group of Bialik et al. (1999). The cell pellet was resuspended in digitonin lysis buffer $\left(75 \mathrm{mM} \mathrm{NaCl}, 1 \mathrm{mM} \mathrm{NaH}{ }_{2} \mathrm{PO}_{4}, 8 \mathrm{mM} \mathrm{Na}_{2} \mathrm{HPO}_{4}, 250 \mathrm{mM}\right.$ sucrose, $190 \mu \mathrm{g} / \mathrm{ml}$ digitonin; $150 \mu \mathrm{l} / 100-\mathrm{mm}$ dish) and incubated on ice for $5 \mathrm{~min}$. The cells were centrifuged (SIGMA 3K30, Germany) for $5 \mathrm{~min}$ at $14,000 \mathrm{rpm}$ at $4^{\circ} \mathrm{C}$, and $1.5 \mu \mathrm{l}$ of protease inhibitor (Protease Inhibitor Mixture Set I, Calbiochem) was added. The pellet was then resuspended in $80 \mu \mathrm{l}$ of radioimmune precipitation buffer ( $1 \%$ Nonidet P- $40,0.5 \%$ sodium deoxycholate, and $0.1 \%$ SDS in phosphate-buffered saline) with protease inhibitor (1:100 dilution). Radioimmune precipitation buffer is more denaturing than NP-40 or Triton X-100 lysis buffer because it contains the ionic detergents SDS and sodium deoxycholate as active constituents. It is particularly useful for membrane disruption. The pellet was then incubated on ice for $30 \mathrm{~min}$, and then centrifuged (SIGMA 3K30, Germany) for $15 \mathrm{~min}$ at $14,000 \mathrm{rpm}$ at $4^{\circ} \mathrm{C}$. The supernatant was saved as the cytosolic fraction, whereas the pellet constituted the mitochondrial fraction.

The soluble protein concentration was determined by the Pierce BCA protein assay (Pierce, Rockford, IL). Protein immunodetection was done by electrophoretic 
transfer of SDS-PAGE separated proteins to PDVF membrane, incubation with primary antibody (antibodies used were against cytochrome $c$ (Mouse monoclonal antibody, catalog no. IMG-101A, Imgenex Corporation, San Diego, USA)) and $\beta$-actin (Mouse monoclonal antibody, catalog no. sc-47778, Santa Cruz Biotechnology, Santa Cruz, CA) in 1:1,000 dilutions for $1 \mathrm{~h}$ at room temperature and secondary antibody (1:5,000 dilution) for $40 \mathrm{~min}$ at room temperature and chemiluminescent second step detection (Santa Cruz Biotechnology, Santa Cruz, CA). Anti-mouse secondary antibodies (catalog no. 20,101) were obtained from Imgenex Corporation, San Diego, USA and used as per recommended antibody dilution of 1:5,000.

\subsection{Determination of caspase activation}

Y-79 cells $\left(1 \times 10^{6}\right)$ were seeded in $25 \mathrm{~cm}^{2}$ culture flasks (Corning, NY, USA) and treated with $5 \mu \mathrm{M} / \mathrm{ml}$ of native DOX, DOX-CNPs, and DOX-CNPs-FA for $48 \mathrm{~h}$ at $37^{\circ} \mathrm{C}$. Thereafter, the cells were collected, washed thrice with PBS (0.1 M, pH 7.4), and then pelleted by centrifugation (SIGMA 3K30, Germany) at 1,000 rpm. The pellet was resuspended in radioimmune precipitation buffer, incubated on ice for $30 \mathrm{~min}$, and spun for $15 \mathrm{~min}$ at $14,000 \mathrm{rpm}$ at $4^{\circ}$ $\mathrm{C}$ to remove the insoluble material. Subsequently, the activities of caspase- 9 and caspase- 3 were determined by western blot analysis as described above. Antibodies used were against caspase-9 (rabbit polyclonal antibody, catalog no. 9502) and caspase-3 (rabbit polyclonal antibody, catalog no. 9662) in 1:1,000 dilutions from Cell Signaling Technology, Inc., MA. Anti-rabbit secondary antibodies (catalog no. 20301) were obtained from Imgenex Corporation, San Diego, USA and used as per the recommended antibody dilution of 1:5,000. Both primary and secondary $\beta$-actin was used in the dilutions mentioned previously.

\subsection{Statistical analysis}

All experiments were repeated at least three times. Statistical analyses were performed using a Student's $t$ test. The differences were considered significant for $p$ values of $<0.05$.

\section{Results}

This study shows that nanoparticulate forms of the anticancer drug doxorubicin can be specifically targeted to cancer cells in a ligand-targeted manner.

\subsection{Nanoparticles characterization}

Chitosan was used to formulate nanoparticles containing the chemotherapeutic drug doxorubicin using a modified ion gelation method. The doxorubicin loading in nanoparticles is $30 \% w / w$ with entrapment efficiency of $\sim 35 \%$, suggesting that most of the doxorubicin added in the formulation is entrapped inside the nanoparticles. The drug EE of the NPs is crucial to justify their clinical applications. The particle size of these nanoparticles is $\sim 300 \mathrm{~nm}$ as determined by the particle size analyzer. This was further confirmed by TEM in which the NPs are seen to be distinct, spherical particles with solid dense structure, with a size of $\sim 200 \mathrm{~nm}$ (Fig. 1a). The nanoparticles appear to be considerably smaller as compared to the average particle size observed with the particle size analyzer, presumably arising from the dry state of the TEM measurements. The nanoparticles were further characterized by SEM. The particles were spherical with a smooth exterior as evident from SEM results (Fig. 1b). Furthermore, the surface morphology of the NPs was also analyzed by AFM which corroborated the results of SEM and confirmed that the NPs had a smooth and spherical appearance (Fig. 1c). The average zeta potential of the NPs was $\sim 30 \mathrm{mV}$ which
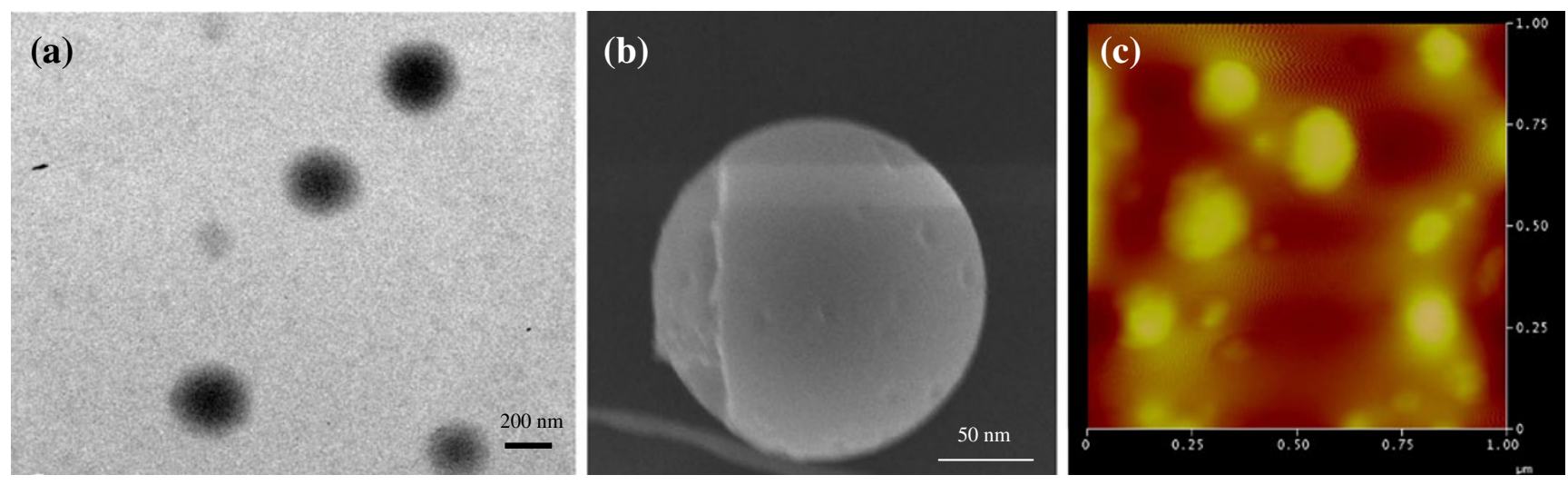

Fig. 1 Physicochemical characterization of CNP-FA. a Transmission electron micrograph. b Scanning electron microscopic images. c AFM images of CNPs-FA 
shows that the NPs are positively charged. Folate-conjugated CNPs also did not show a significant variation in the size and zeta potential values.

The conjugation of folic acid to the surface of NPs was confirmed by NMR (Fig. 2). It is apparent that the spectrum of the conjugate contains signals originating from folic acid and chitosan. The signals at $3.5-4.0 \mathrm{ppm}$ are due to hydrogen bonded to the carbon atoms 3, 4, 5, and 6 of the glycopyranose unit and that at $1.9-2.0 \mathrm{ppm}$ correspond to the hydrogen atoms of the methyl moieties of the acetamido groups of chitosan (Ji et al., 2009). Moreover, the signals at 6.7 and $7.6 \mathrm{ppm}$ correspond to the para- aminobenzoic acid (PABA) from the folate, and the signal at $8.7 \mathrm{ppm}$ corresponds to the pteridine moiety proton from the folate (Kim et al. 2007). The chemical modification of NPs by folic acid also resulted in the appearance of a characteristic peak at $7.4 \mathrm{ppm}$ (Wan et al. 2008). The conjugation efficiency of folic acid to CNPs as determined by UV-Visible spectrophotometer revealed that $\sim 0.33 \mathrm{mg}$ of FA was conjugated per milligram of CNPs. The schematic representation of folic acid conjugated to chitosan is depicted in Fig. 2c.

The IR spectra of folic acid, doxorubicin, and DOXCNPs-FA are shown in Fig. 3a. FTIR spectra confirmed the
Fig. $2{ }^{1} \mathrm{H}$ NMR spectra of a chitosan, b CNP-FA conjugate, and $\mathbf{c}$ schematic representation of folic acid conjugated to chitosan (a)

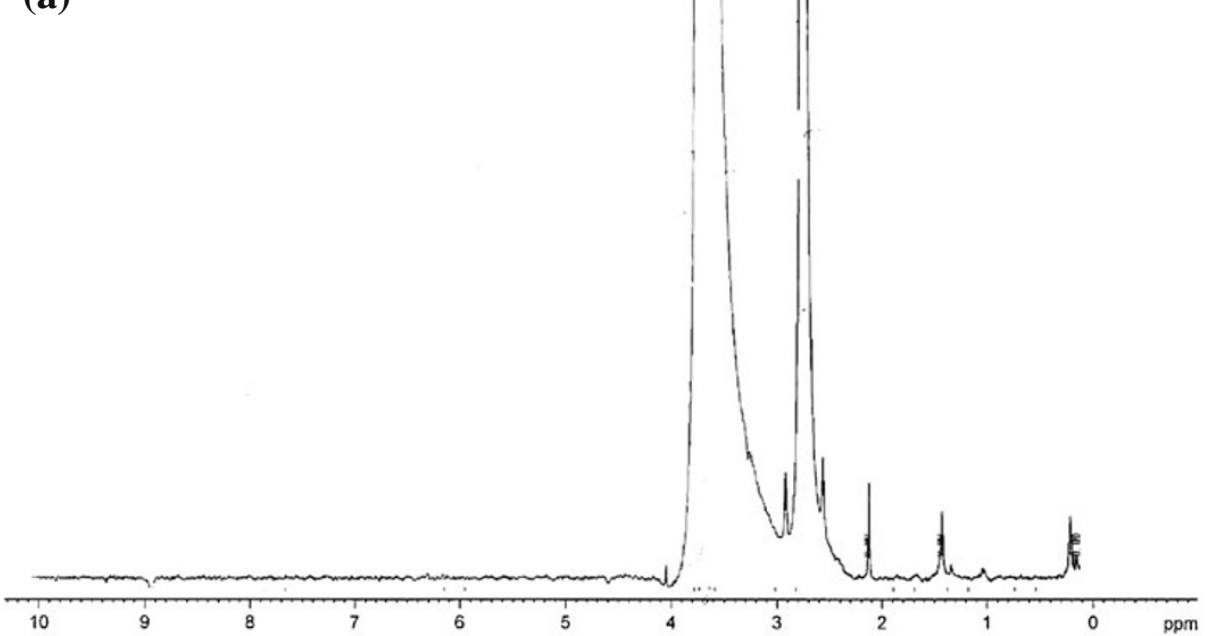

(b)

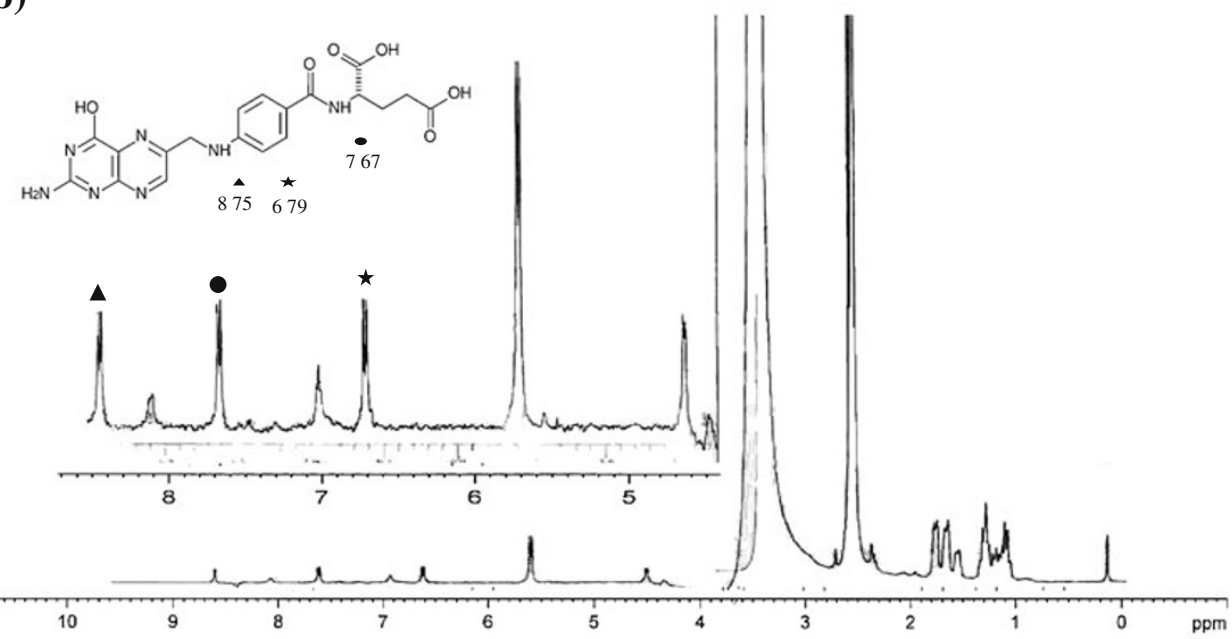

(c)

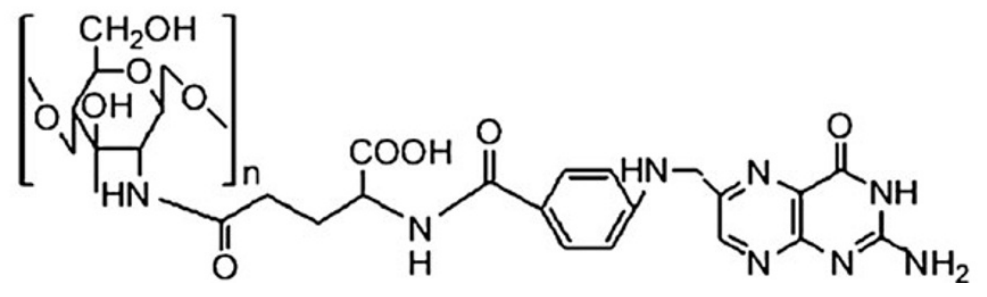


(a)

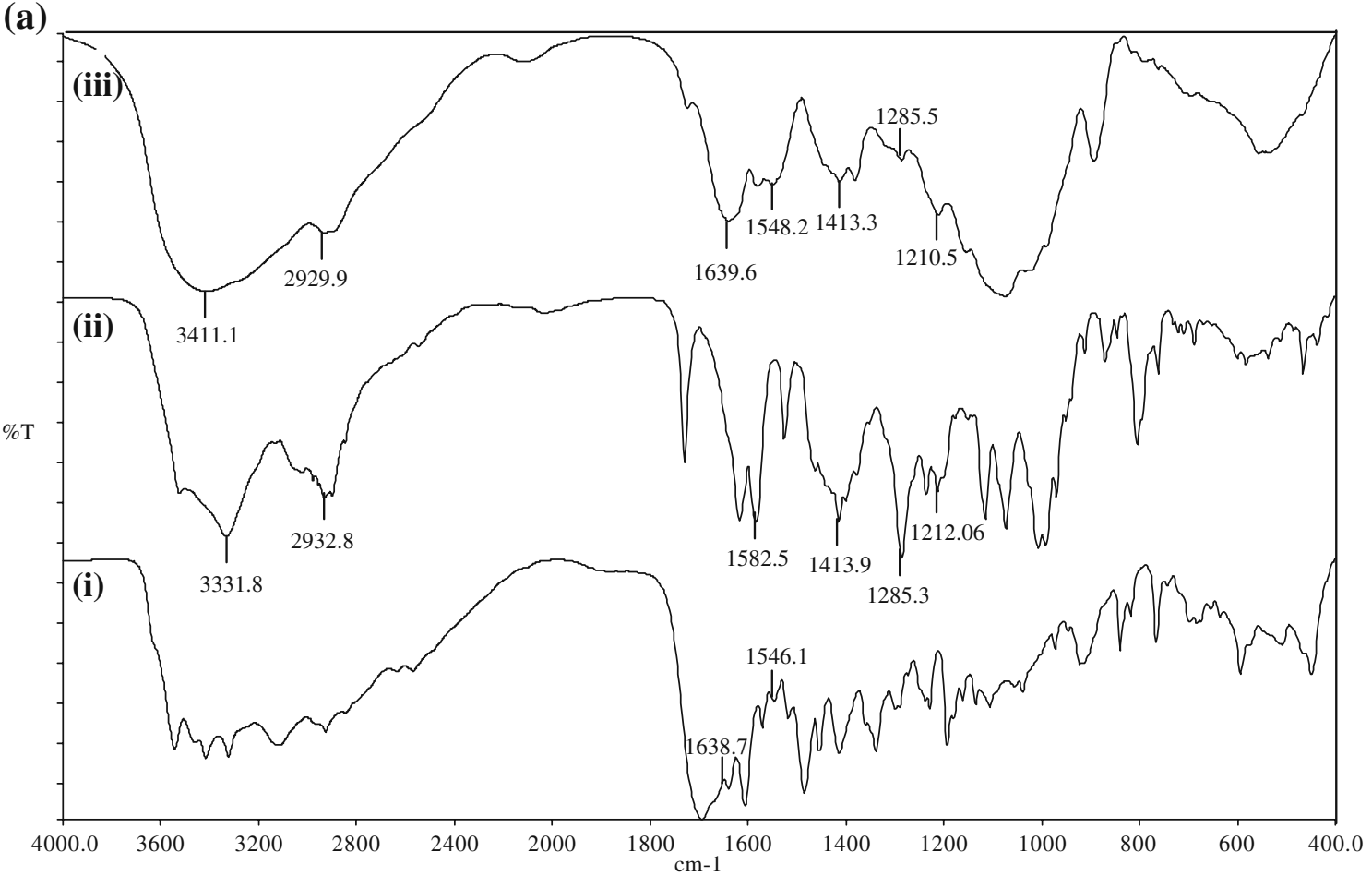

(b)

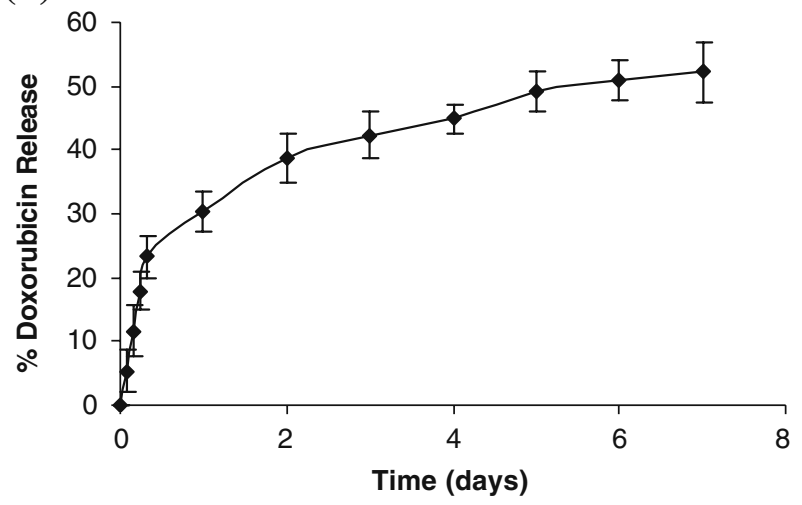

Fig. 3 a Nanoparticle characterization by FTIR. Figure depicts FTIR spectra of (i) folic acid, (ii) doxorubicin, and (iii) DOX-CNPs-FA. b In vitro DOX release profiles from CNPs. Data represent mean \pm S.D., $n=3$

successful conjugation between CNPs and FA as is evident by the presence of the characteristic peaks of folic acid at $\sim 1,638 \mathrm{~cm}^{-1}$ (-CONH amide band II) and $\sim 1,546 \mathrm{~cm}^{-1}$ (-NH amide band II) in DOX-CNPs-FA. Furthermore, the absorption of amide band II at $1,638 \mathrm{~cm}^{-1}$ increased, which may be due to the formation of the amide linkage between the amino group on the CNPs and the carboxyl group of FA (Sahu et al. 2010). FTIR is also one of the best techniques to know the chemical stability of the encapsulated drug inside the NPs as is evident from studies done by our group and others (Misra and Sahoo 2010; Mundargi et al. 2007). Thus, FTIR was also done to assess the chemical stability of DOX in our nanoparticulate formulations. Native DOX showed characteristic bands due to presence of different functional groups. A band appearing at $23,331 \mathrm{~cm}^{-1}$ is due to $\mathrm{O}-\mathrm{H} / \mathrm{N}-\mathrm{H}$ stretching vibrations, while those observed at $\sim 2,932 \mathrm{~cm}^{-1}$ is due to the $\mathrm{C}-\mathrm{H}$ stretching vibration. Bands at $\sim 1,582$ and $\sim 1,413 \mathrm{~cm}^{-1}$ are due to aromatic N-H bending vibrations and $\mathrm{C}-\mathrm{H}$ bending vibrations, respectively. The bands at $\sim 1,285$ and $\sim 1,212 \mathrm{~cm}^{-1}$ belong to C-N stretching vibrations. These distinctive bands of native DOX were also present in DOX-loaded NPs which indicated the chemical stability of DOX in the nanoparticulate formulation (Misra and Sahoo 2010). The average cumulative percent release profile of DOX from the NPs at prefixed time intervals is represented in Fig. 3b. It was apparent that DOX release in vitro showed a very rapid initial burst, and then followed by a slow release. DOX-CNPs showed biphasic release kinetics: initially a faster release profile wherein about $25 \%$ of the drug is 
released in $12 \mathrm{~h}$ and thereafter sustained release for days ( $~ 50 \%$ of DOX was released in 7 days).

\subsection{Effects of DOX on in vitro cytotoxicity, apoptosis,} and Y-79 cell cycle progression and proliferation

To examine the antitumor activity of doxorubicin in human retinoblastoma Y-79 cells, exponentially dividing cells were treated with increasing concentrations of native DOX, DOXCNPs, and DOX-CNPs-FA, and the cell viability was measured. The in vitro viability of Y-79 cells after treatment with various concentrations of the different formulations is shown in Fig. 4. Though, DOX caused marked growth inhibition and significantly decreased cell viability, it was evident that the NP formulation, at all concentrations, demonstrated significant cytotoxicity versus the native drug. Moreover, the figure clearly demonstrates the targeting effect of the folate decoration on DOX-CNPs as the $\mathrm{IC}_{50}$ value decreased to $3.06 \mu \mathrm{M}$ as compared to DOX-CNPs $(10.2 \mu \mathrm{M})$ and native DOX $(15.11 \mu \mathrm{M})$. As apoptosis is considered the key mechanism linked with chemotherapyinduced cell death, the extent of apoptosis was analyzed by Annexin $\mathrm{V}$ analysis of externalized phosphatidylserine. As evident from Fig. 5, all the CNP formulations showed greater apoptotic effect than native DOX. The extent of apoptosis was $60.2 \%$ for DOX-CNPs-FA, $38.04 \%$ for DOX-

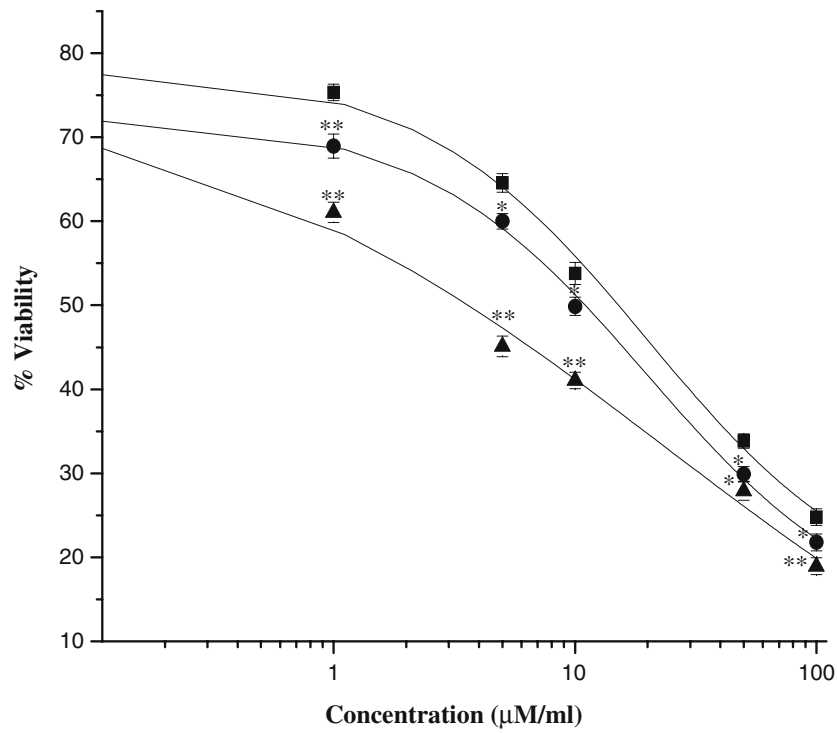

Fig. 4 Evaluation of in vitro cytotoxicity by the MTT assay. Different concentrations of doxorubicin were added either as solution or encapsulated in nanoparticles (DOX-CNPs, DOX-CNP-FA) to the wells with medium as control in Y-79 cell line. Medium was changed at 2 days and then every alternate day thereafter with no further dose of the drug added. The extent of growth inhibition was measured at 5 days by the MTT assay. Data as mean \pm S.E.M., $n=6 .{ }^{*} p<0.005$, DOX in solution versus DOX-CNPs and DOX-CNP-FA. ${ }^{*} p<0.05$, DOX in solution versus DOX-CNPs and DOX-CNP-FA (black square-native DOX, black circle-DOX-CNPs, black triangle-DOX-CNP-FA). Void CNPs had no significant toxicity in the Y-79 cell line
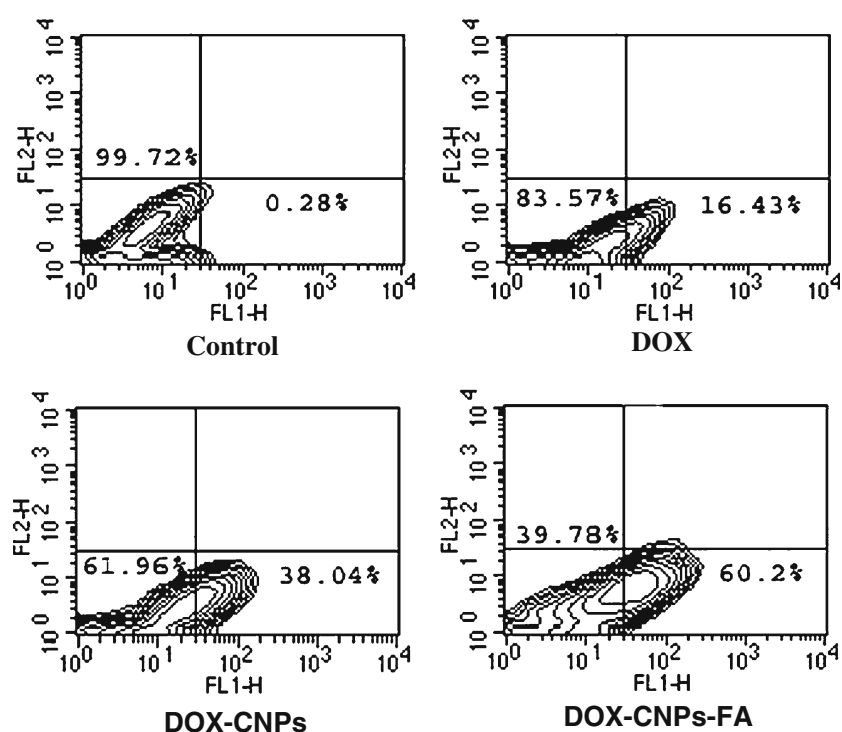

Fig. 5 Induction of apoptosis in Y-79 cell line by native DOX, DOXCNPs, and DOX-CNP-FA. Cells were treated with $5 \mu \mathrm{M}$ of native DOX and equivalent concentrations of DOX in NPs (DOX-CNP and DOX-CNP-FA) for $48 \mathrm{~h}$ and were then stained with Annexin V to access the apoptotic potential by flow cytometry. Results are representative of one of three independent experiments

CNPs, and $16.43 \%$ for native DOX clearly indicating the efficacy of DOX-CNP-FA over other formulations. Although it was apparent that DOX was cytotoxic to Y-79 cells, the sustained growth-inhibitory effects observed by the cell viability assay indicate that DOX might also affect cell proliferation. To assess whether DOX induced growth inhibition, we evaluated the effect of native DOX, DOXCNPs, and DOX-CNPs-FA on cell cycle progression in Y-79 cells by flow cytometry. As evident from the enhanced G2/M phase inhibition, folate-decorated DOX-CNPs do significantly exert a greater antiproliferative effect than DOX-CNPs as well as native DOX (Fig. 6). Thus, the results demonstrate that DOX inhibits tumor cell growth by exerting greater cytotoxic effects on Y-79 cells.

\subsection{Cellular uptake as a function of particle surface modification}

As Y-79 cells have a high level of the folic acid receptor on their surface (Kansara et al. 2008), the targeting effect of folate-decorated NPs can be evaluated by investigating the cellular uptake of the NPs. The uptakes of native DOX, DOX-CNPs, and DOX-CNPs-FA by Y-79 cancer cells were studied by flow cytometry under in vitro conditions. As shown in Fig. 7a, b, flow cytometry measurements indicate that about $31.23 \%$ of the cells showed enhanced fluorescence when incubated with folate-decorated NPs, which was around sixfold greater than the native DOX (5.01\%). DOXCNPs also demonstrated significantly greater uptake 
Fig. 6 Cell cycle analysis by flow cytometry. For $48 \mathrm{~h}, 1 \times$ $10^{5}$ cells $/ \mathrm{ml}$ were treated with $5 \mu \mathrm{M}$ of native DOX and equivalent concentrations of DOX in NPs (DOX-CNP and DOXCNP-FA). Thereafter, to the treated cells, $20 \mu \mathrm{g} / \mathrm{ml}$ of propidium iodide solution was added and incubated at room temperature in dark for $30 \mathrm{~min}$ before flow cytometric analysis. Cell cycle distribution was determined by analyzing 15,000 ungated cells using a FACScan flow cytometer. Content of DNA is represented on the $x$-axis; number of cells counted is represented on the $y$-axis. Results are representative of one of three independent experiments
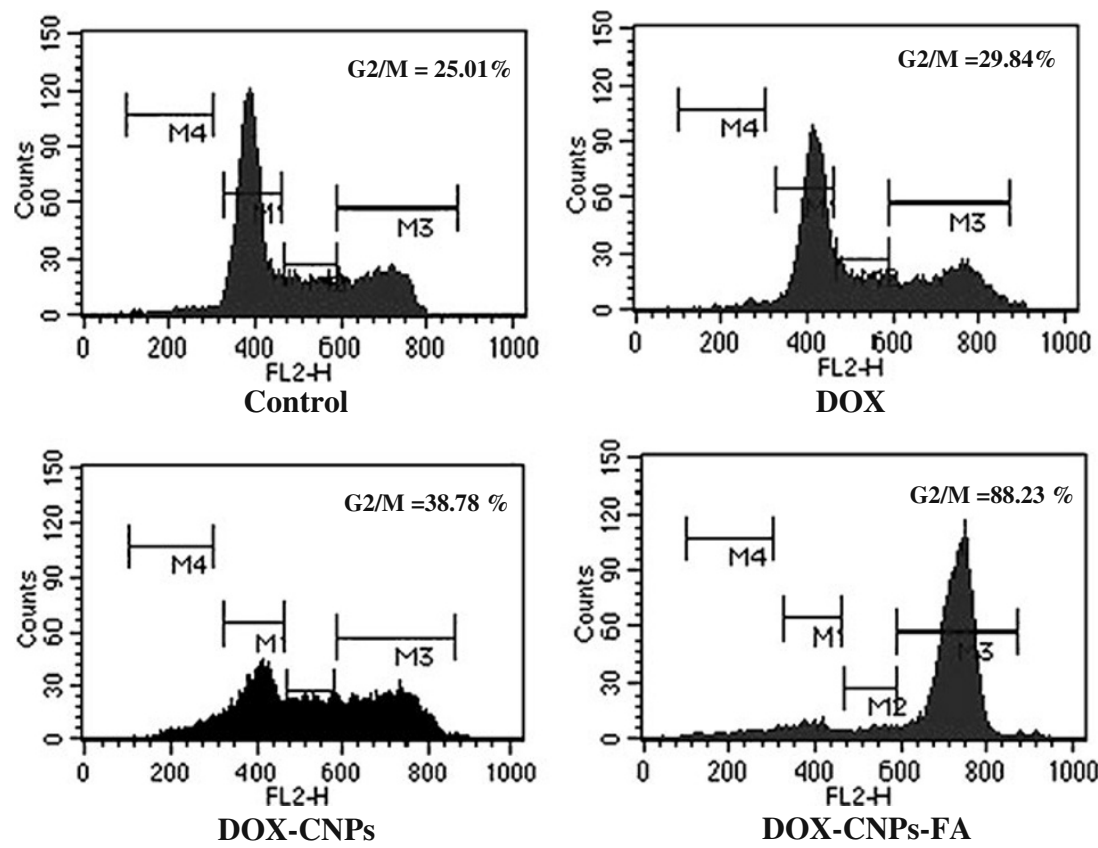

$(13.24 \%)$ than the native drug. To verify that the uptake is mediated via the folate receptor, a competitive experiment using different amounts of native folic acid in cell culture medium together with folate-decorated NPs was performed. As shown in Fig. 7c, the number of Y-79 cells that had internalized the FA-functionalized NPs decreased with increasing concentrations of free FA. At the highest free folic acid concentration evaluated $(3 \mathrm{mM})$, the MFI value decreased around fivefold as compared to the value measured in the absence of free FA.

Targeting effect of DOX-CNPs-FA was also investigated by using confocal laser scanning microscopy to further confirm the enhanced intracellular uptake of the folate-decorated NPs. Y-79 cells, incubated with free DOX in solution, demonstrated drug internalization within $2 \mathrm{~h}$ of incubation, but with increase in incubation time, the fluorescent intensity was reduced slowly. DOX-CNPs-FA-loaded nanoparticles on the other hand, were more strongly stained with clear visualization of the internalized NPs, and in addition, they showed a significant increase in fluorescence intensity with incubation time with strong fluorescence even after 8 days of treatment as compared to the native DOX (Fig. 7d). These findings are in agreement with the previous results obtained for quantitative measurement. These quantitative and qualitative results of the cellular uptake of the NPs provide strong evidence for the targeting effect of folate decoration for Y-79 cells.

3.4 Drug-induced changes in mitochondrial transmembrane potential

Mitochondrial changes, including variations in mitochondrial membrane potential $\left(\Delta \psi_{\mathrm{m}}\right)$, are the key events during drug-mediated apoptosis (Zamzami et al. 1995). To delineate this mechanism, the lipophilic cation JC-1 was chosen as it is more specific for mitochondria than other fluorescent dyes such as $\mathrm{DiOC}_{6}(3)$ or Rhodamine 123 (Ly et al. 2003; Salvioli et al. 1997), and this was used to determine whether DOX induces alterations in the $\Delta \psi_{\mathrm{m}}$. As compared to untreated cells, DOX-treated cells exhibited a dramatic decrease in the population of cells with J-aggregates $(93.6 \%)$ and subsequent increase in the monomeric form $(6.18 \%)$ indicating rapid depolarization of the mitochondrial membranes. The alterations in the $\Delta \psi_{\mathrm{m}}$ were much more evident in the case of NP formulations, especially for the folate-decorated NPs (70.2\%, JC-1 aggregates and 29.7\%, JC-1 monomers) for the same concentration of drug exposure (Fig. 8).

\subsection{Kinetic analysis of drug-induced mitochondrial translocation of cytochrome $c$}

Mitochondria play an essential role in apoptosis triggered by various chemical agents (Sareen et al. 2006). Cytochrome $c$ is normally localized in the space between the outer and inner mitochondrial membrane and is only released into the cytosol in the setting of apoptosis (Kluck et al. 1997). The mitochondrial response includes the release of cytochrome $c$ into the cytosol where it binds to Apaf-1, allowing the recruitment of caspase-9 and the formation of an apoptosome complex, resulting in caspase3 activation and execution of cell death (Green and Reed 1998). To determine whether DOX initiates this cell death mechanism, we tested whether it triggers the release of cytochrome $c$ from the mitochondria and the amount of 
(a)

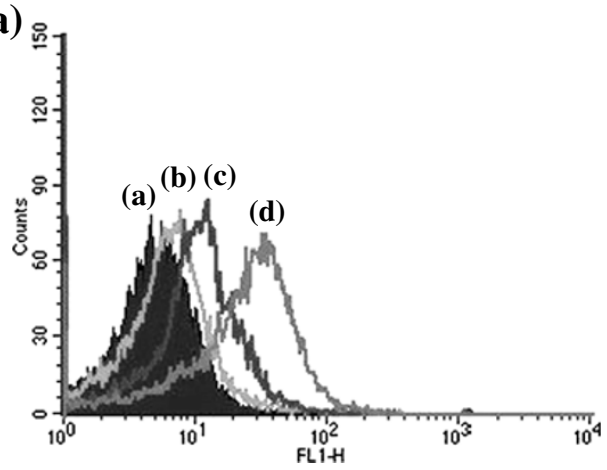

(c) (b)

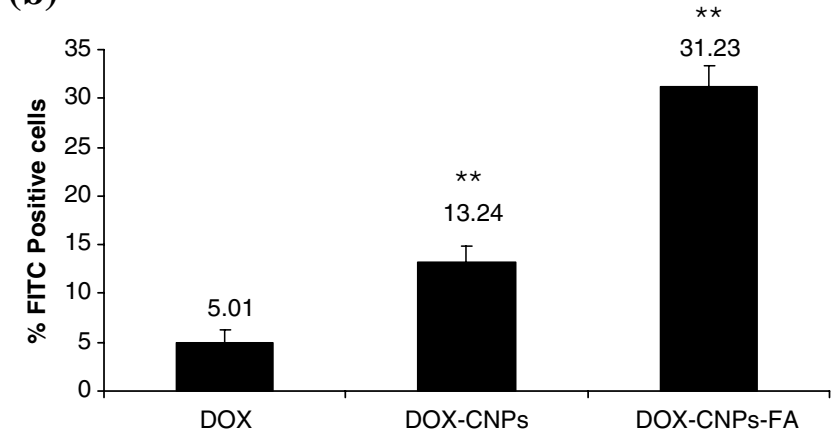

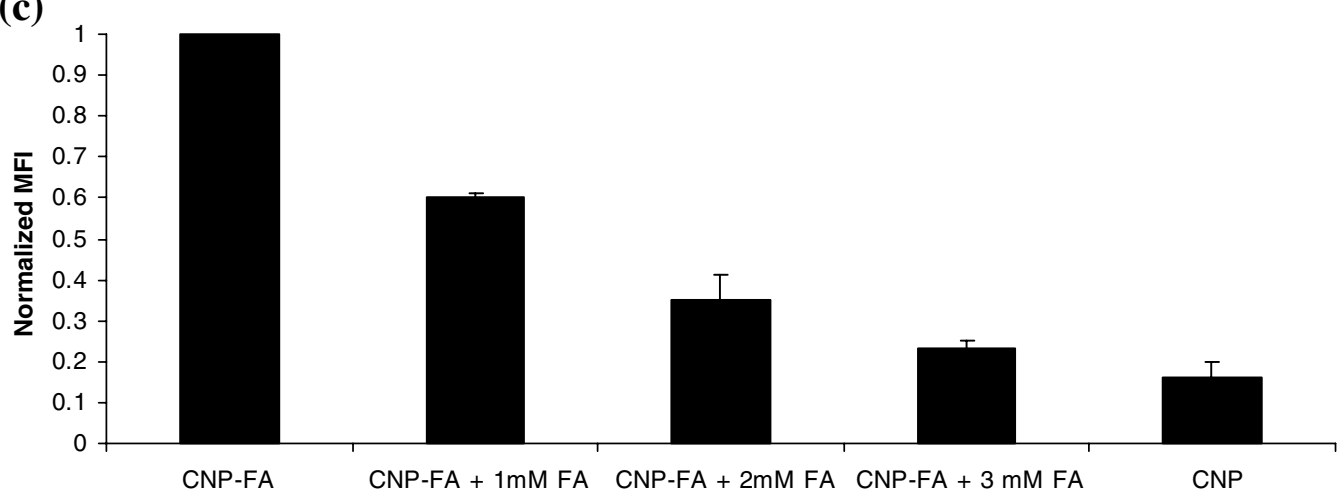

(d)

$2 \mathbf{h}$

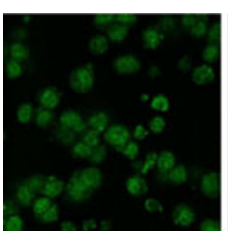

DOX

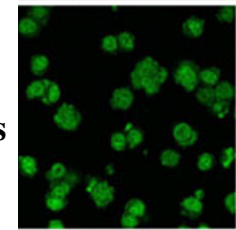

DOX-CNPs

DOX-CNPs-FA
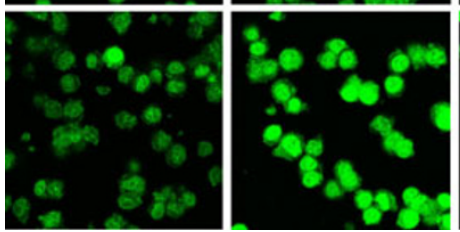

Fig. 7 Cellular uptake as a function of particle surface modification a folic acid conjugation increases nanoparticle endocytosis in Y-79 cells. Y-79 cells were incubated with native DOX and nanoparticles at a dose of $300 \mu \mathrm{g} / \mathrm{ml}$ for $2 \mathrm{~h}$ and the number of Y-79 cells with the endocytosed CNPs was detected by flow cytometry. $a$ Control. $b$ DOX. $c$ DOX-CNPs. $d$ DOX-CNPs-FA. Results are representative of one of three independent experiments. b Bar graph depicts the data from Fig. 7a demonstrating the uptake efficiency of various formulations. Data as mean \pm S.D., $n=3 . * * p<0.005$, DOX in solution versus DOX-CNPs and DOX-CNP-FA. c Competitive inhibition of DOX-CNP-FA uptake by the addition of native FA. Y-79 cells were cultured overnight with $0-3 \mathrm{mM}$ of native folic acid after which the
5 days 8 days



cells were left untreated (control) or incubated with $300 \mu \mathrm{g} / \mathrm{ml}$ of nanoparticles for $2 \mathrm{~h}$. Mean fluorescence intensity (MFI) of DOX fluorescence in the cells were measured and the value normalized to particle endocytosis of Y-79 cells. Data represent mean \pm S.D., $n=3$. d Time course study of intracellular retention of DOX-loaded NPs in Y79 cells. Cells were treated with $5 \mu \mathrm{M}$ of native DOX and equivalent concentrations of DOX in NPs (DOX-CNP and DOX-CNP-FA) in the growth medium. Cells treated with DOX in solution showed a decrease in green fluorescence intensity with incubation time, whereas DOX-CNPs demonstrated an increase with FA-conjugated CNPs demonstrating the fluorescence of the drug lasting up to 8 days. Results are representative of one of three independent experiments 

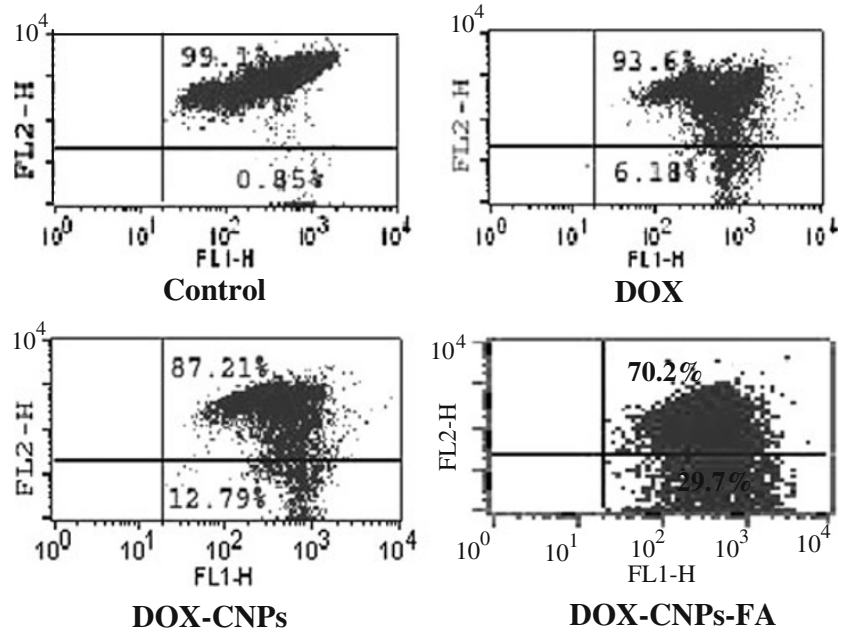

Fig. 8 DOX disrupts normal mitochondrial membrane potential. Y-79 cells were treated with $5 \mu \mathrm{M}$ of native DOX and equivalent concentrations of DOX in NPs (DOX-CNP and DOX-CNP-FA) for $48 \mathrm{~h}$ and were then stained with $\mathrm{JC}-1$ to access the mitochondrial transmembrane potential by flow cytometry. Results are representative of one of three independent experiments

cytochrome $c$ released was examined in the cytosolic and mitochondrial fractions by western blot analysis. DOX induced slight release of cytochrome $c$ into the cytosol as early as $2 \mathrm{~h}$ after the treatment (Fig. 9a). In contrast, both DOX-loaded NPs induced a greater amount of cytochrome $c$ release, the effect being more prominent in case of DOXCNPs-FA. This may be due to the substantial loss of $\psi_{\mathrm{m}}$, and as a consequence, the mitochondrial membranes are easily damaged leading to a massive leakage of cytochrome $c$. It was further observed that the quantity of the protein released increased with time and after $48 \mathrm{~h}$, large quantities of the protein accumulated in the cytosol. Furthermore, it was observed that folate-decorated NPs were most effective in causing the release of cytochrome $c$ at all time intervals (Fig. 9a). The temporal profile of cytosolic accumulation of cytochrome $c$ parallels its release from the mitochondria. From these results, it was evident that DOX-induced apoptotic death is mediated by mitochondria-dependent signaling pathways in Y-79 cell line.

\subsection{Participation of caspase-9 and caspase-3 in DOX-induced apoptosis}

Loss of $\psi_{\mathrm{m}}$ and cytochrome $c$ release by numerous apoptotic stimuli including chemotherapeutic drugs lead to apoptosis which is executed by the linked activation of initiator (e.g., caspase-9) and effector caspases (e.g., caspase-3; Earnshaw et al. 1999). Caspase activation was assessed by western blotting after $48 \mathrm{~h}$ in accordance to the peak cytochrome $c$ release, utilizing antibodies that detect both the procaspase as well as the cleaved caspase fragments. Based on these criteria, Fig. 9b shows evidence for DOX-induced activation of the initiator caspase (caspase-9) and the effector caspase (caspase-3). It was evident that all formulations caused activation of caspases, with the effects being most prominent in case of DOX-CNPs-FA, which caused greater cleavage of the procaspases into the active caspases.

\section{Discussion}

Targeting is especially relevant in case of cancer therapies, as most of the commonly used anticancer drugs have serious side effects due to non-specific actions on healthy cells. The folate receptor, which normally is expressed only at the luminal surface of polarized epithelia, has been found to be overexpressed on the surface of several cancer cells, including retinoblastoma (Kansara et al. 2008; Leamon and Low 2001; Leamon and Reddy 2004). Thus, due to this distinguishing feature between normal and cancer cells, folic acid has emerged as an attractive targeting ligand for selective delivery, and thus is used for the surface conjugation to NPs. In this paper, our goal was to prepare highly monodisperse polymeric nanoparticles with high doxorubicin loading and folate decorated on the NP surface for site-specific targeting. These NPs, in addition, may be specifically suitable for ocular drug delivery because of its excellent mucoadhesive properties and its ability to enhance the penetration of large molecules across mucosal surface (Sahoo et al. 2008).

In our studies, doxorubicin-loaded chitosan NPs of around $300 \mathrm{~nm}$ were synthesized and developed for the treatment of retinoblastoma (Fig. 1). These NPs were then surface conjugated with FA in order to achieve site-specific targeting. Conjugation of FA to the NP surface was confirmed by NMR and FTIR (Figs. 2 and 3a). A typical biphasic release pattern of doxorubicin from the NPs was obtained which may be due to the faster release of the surface-adsorbed drug (burst effect) and slower release thereafter, as the drug gradually diffuses from the NPs (Fig. 3b). A sustained release of the drug from the NPs is important as a continuous exposure of the tumor cells to anticancer drugs of a relatively lower but safer concentration that gives little chance for the tumor blood vessels to grow, resulting in much better efficacy and fewer side effects than intermittent chemotherapy.

Once the NPs were synthesized and characterized, the cytotoxic potential of the various formulations was determined as the efficacy of the formulations to defeat cancer cells is reflected by their cytotoxicity. A quantitative evaluation of in vitro therapeutic effect of a dosage form is $\mathrm{IC}_{50}$, which is defined as the drug concentration needed to kill $50 \%$ of the incubated cells in a designated time 
period. It can be calculated from the in vitro cellular viability data that judging by $\mathrm{IC}_{50}$ after the treatment, the $\mathrm{IC}_{50}$ is $15.11 \mu \mathrm{M}$ for native DOX, $10.2 \mu \mathrm{M}$ for DOX-CNP formulation, and $3.06 \mu \mathrm{M}$ for folate decorated DOX-CNP formulation, which means that DOX-CNPs-FA is approximately threefold more effective than the NP formulation and approximately fivefold more effective than the native DOX (Fig. 4). It is thus clear that folate-conjugated CNPs demonstrated higher cytotoxicity than the NP formulation and native doxorubicin, which means that for the same therapeutic effect, the drug needed for the folate-conjugated CNP formulation could be much less than the NP formulation and native doxorubicin itself. Nanoparticles may be more cytotoxic than the free drug as the polymeric envelope protects the drug and prevents the drug from being degraded by the harsh in vivo environment (Panyam and Labhasetwar 2003; Torchilin 2005). In comparison, the free drug in solution is vulnerable to all such conditions and maybe degraded and as a result is not able to exert its antiproliferative effects to the maximum. Moreover, the nanoparticles form a drug depot wherein the drug is released slowly as compared to the native drug, and thus, a continuous exposure and sustained release of the drug over a period of time is more effective. This may also be the reason that both the formulations of CNPs showed greater apoptosis and enhanced cell cycle arrest than the native DOX at the same concentration, which further corroborated the results of the cytotoxicity assay (Figs. 5 and 6). The development of the CNPs formulation of DOX, thus, can enhance the therapeutic effect as well as prevent the toxic effects of the drug applied at high concentrations.

Moreover, it was evident from the various cytotoxicity assays that folate-conjugated CNPs is a better candidate for drug delivery as it provides enhanced cytotoxicity which may be due to greater cellular uptake by the folate receptors. To validate this hypothesis, the cellular uptake of the various formulations by Y-79 cells was determined in vitro to demonstrate the penetration of the CNPs into the cells and the targeting effects of the FA-decorated CNPs. Furthermore, a competitive experiment using different concentrations of FA together with DOX-CNPs-FA was performed to verify that the uptake was mediated by the FA receptor. The uptake experiments confirmed the manifoldenhanced uptake of DOX-CNPs-DOX as compared to

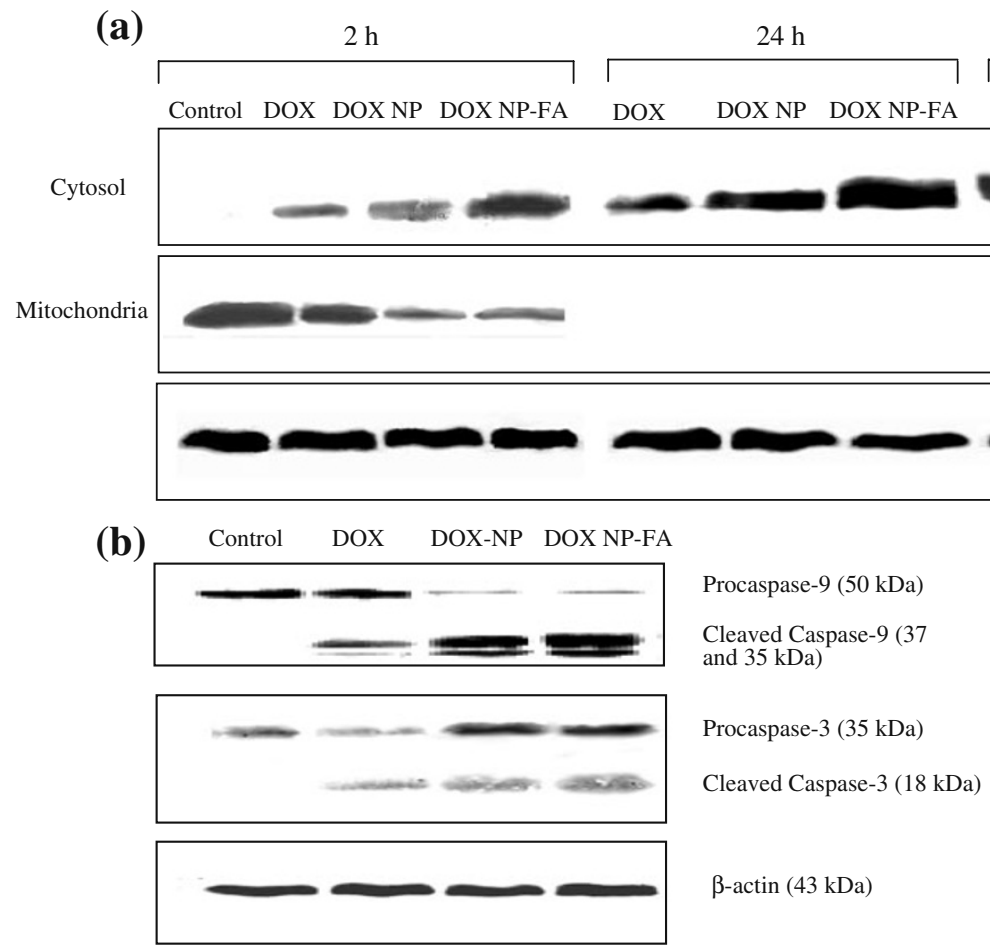

Fig. 9 Western blot analysis to determine the apoptotic mechanism of doxorubicin a DOX causes cytochrome $c$ release from mitochondria. Y-79 cells were treated with $5 \mu \mathrm{M}$ of native DOX and equivalent concentrations of DOX in NPs (DOX-CNP and DOX-CNP-FA) for 2, 24 , and $48 \mathrm{~h}$. Cytosolic and mitochondrial fractions from intact cells were prepared and analyzed for cytochrome $c$ levels by immunoblotting using an anti-cytochrome $c$ antibody. Samples obtained from the time course of different fractions (cytosol or mitochondria) were adjusted for equal protein loading by determination of concentrations with the Bradford assay. $\beta$-actin was used as a standard for the equal loading of protein in the lanes. b DOX activates caspase-9 and caspase-3. Y-79 cultures were treated with $5 \mu \mathrm{M}$ of native DOX and equivalent concentrations of DOX in NPs (DOX-CNP and DOXCNP-FA) for $48 \mathrm{~h}$. Thereafter, the cells were harvested and lysed at the indicated times after treatment, and the protein extracts were extracted and analyzed by western blot for the presence of activated caspase- 9 and caspase- 3 . $\beta$-actin was used as a standard for the equal loading of protein in the lanes 
DOX-CNPs and the native DOX (Fig. 7a, b). Besides, the inhibition of uptake of folate-decorated CNPs by free FA in a dose-dependent manner demonstrates that the particle uptake is mediated by the FA receptor (Fig. 7c). Thus, the key for the success of the targeted formulation is due to FA that conveys targeting properties to the carrier, which involves the cell-folate receptor interaction, internalization, and intracellular drug release. Though, we agree that even at a folic acid concentration of $3 \mathrm{mM}$, some internalization of the NPs occurs which may be due to the inherent ability of CNPs to enter the cells by endocytosis. Confocal microscopic studies also demonstrated greater intracellular retention of the DOX-CNPs-FA as compared to the DOXCNPs and native DOX (Fig. 7d). Thus, the greater antiproliferative effect of DOX-loaded CNPs-FA can be very well correlated with the duration of its intracellular retention. Our experimental conclusions that FA causes ligand specific internalization and enhanced endocytosis of NPs which leads to greater cytotoxicity can also be supported by similar findings of various research groups. Folate decorated poly (lactide)-vitamin E TPGS nanoparticles for the targeted delivery of paclitaxel was synthesized by the group of Pan et al. in which they have shown the enhanced advantages of the NP formulations versus the native drug in achieving better therapeutic effect (Pan and Feng, 2008). The advantage of folate targeting was also exploited by the group of Rosenholm et al. in which they synthesized folate-conjugated porous hybrid silica nanoparticles for targeting to cancer cells. Significantly enhanced uptake of the formulated NPs by the cancer cells supports the enhanced endocytosis of the NPs by folate receptor expressing cells (Rosenholm et al. 2009). In another study by Liu et al., in which folic acidconjugated nanoparticles of mixed lipid monolayer shell and biodegradable polymer core for targeted delivery of docetaxel was synthesized, they showed that folic acidconjugated NPs facilitate the targeted delivery of docetaxel as well as enhanced cytotoxicity (Liu et al. 2009).

Doxorubicin is one of those cytotoxic drugs that are known to mediate apoptosis through the intrinsic mitochondrial pathway in many cancer cell lines (Guo et al. 2000; Kluza et al. 2004; Liu et al. 2010). In our studies this pathway was investigated as these studies might provide the molecular evidence of enhancement of apoptosis by the nanoparticles. As already discussed, the mitochondrial-dependent apoptotic pathway is initiated through the disruption of the mitochondrial membrane potential. This disruption leads to the release of cytochrome $c$ and the formation of the apoptosome complex (cytochrome $c /$ Apaf-1/caspase-9) and activation of the caspase cascade. The changes in mitochondrial membrane potential were analyzed by the JC-1 dye that can be used to predict the polarization state of the mitochondria. It was evident that due to the targeting effects, Y-79 cells were more sensitive to FA-conjugated NPs than the DOX-CNPs and the native DOX (Fig. 8). Due to the collapse of $\psi_{\mathrm{m}}$ as a result of the leakiness of the inner mitochondrial membrane, cytochrome $c$ is released into the cytosol, which appears to precede the activation of caspase-9 and caspase-3. The temporal release profile of cytochrome $c$ suggests that greater quantity of the protein accumulated in the cytosol after treatment with DOX-CNPs-FA (Fig. 9a). This was also followed by enhanced activation of both the caspases, which suggests its advantage over DOX-CNPs and native DOX (Fig. 9b).

The mechanism of apoptosis by doxorubicin in retinoblastoma has not been studied till date. Taken together, our results point to a general mechanism of apoptosis induction by DOX in Y-79 cells that involves a progressive loss of mitochondrial membrane potential and activation of the intrinsic mitochondrial/caspase-9 specific pathway, confirming previous findings from other groups in vivo as well as in different cancer cell lines (Childs et al. 2002; Gao et al. 2001; Kluza et al. 2004; Liu et al. 2010). In all cases, FA-decorated NPs showed superior efficacy as a drug delivery system as compared to DOX-CNPs and native DOX, which suggests that targeting of Y-79 with folic acid may play a pivotal role in increasing the therapeutic efficacy of drugs as well as decreasing the deleterious side effects by considerable reducing the dosage. Though, these carriers do hold promise as a drug delivery system for the ocular tissues, further studies are warranted to determine the in vivo efficacy of these folate-decorated DOX-CNPs for the treatment of retinoblastoma.

\section{Conclusion}

In this study, FA-conjugated and DOX-loaded CNPs are prepared and characterized for targeting the cancer cells rich in folate receptors on their surface. DOX-loaded CNPs with surface-conjugated FA, demonstrated a superior cellular uptake over non-targeted NPs due to FA receptormediated endocytosis, which also resulted in an increased cytotoxicity. FA-targeted CNPs also showed enhanced apoptosis and cleavage of downstream procaspases into active caspases for the augmentation of apoptosis. Thus, this work established the better efficacy of DOX-CNP-FA due to the targeting ligand (FA), and this work may pave the way for targeted therapy for the treatment of retinoblastoma via a safe drug delivery vehicle and with minimal undesirable effects. However, it should be pointed out that this is only a proof-of-concept investigation for design of FA-conjugated and drug-loaded CNPs. Further in vivo investigation should be carried out to determine the therapeutic efficacy of these CNPs. 
Acknowledgments Department of Biotechnology (DBT), New Delhi, India is acknowledged for the award of Junior Research Fellowship (JRF)/Senior Research Fellowship (SRF) to SP. Financial support to the Institute from the Department of Biotechnology (DBT) and research grants BT/04(SBIRI)/48/2006-PID and BT/ PR7968/MED/14/1206/2006 from DBT to SKS is also gratefully acknowledged.

\section{References}

Abramson DH (1990) Retinoblastoma 1990: diagnosis, treatment, and implications. Pediatr Ann 19:387-395

Abramson DH, Frank CM (1998) Second nonocular tumors in survivors of bilateral retinoblastoma: a possible age effect on radiation-related risk. Ophthalmology 105:573-579

Al-Joudi FS, Alias IZ, Samsudin AR (2005) The effects of chemotherapeutic drugs on viability, apoptosis, and survivin expression in MCF-7 cells. Acta Histochem Cytochem 38:323-330

Amendola BE, Markoe AM, Augsburger JJ et al (1989) Analysis of treatment results in 36 children with retinoblastoma treated by scleral plaque irradiation. Int J Radiat Oncol Biol Phys 17:63-70

Bialik S, Cryns VL, Drincic A et al (1999) The mitochondrial apoptotic pathway is activated by serum and glucose deprivation in cardiac myocytes. Circ Res 85:403-414

Calvo P, Remunan-Lopez C, Vila-Jato JL et al (1997a) Novel hydrophilic chitosan-polyethylene oxide nanoparticles as protein carriers. J Appl Polymer Sci 63:125-132

Calvo P, Vila-Jato JL, Alonso MJ (1997b) Evaluation of cationic polymer-coated nanocapsules as ocular drug carriers. Int J Pharm 53:41-50

Chan HS, Canton MD, Gallie BL (1989) Chemosensitivity and multidrug resistance to antineoplastic drugs in retinoblastoma cell lines. Anticancer Res 9:469-474

Childs AC, Phaneuf SL, Dirks AJ et al (2002) Doxorubicin treatment in vivo causes cytochrome $\mathrm{C}$ release and cardiomyocyte apoptosis, as well as increased mitochondrial efficiency, superoxide dismutase activity, and Bcl-2:Bax ratio. Cancer Res 62:4592-4598

Cossarizza A, Baccarani-Contri M, Kalashnikova G et al (1993) A new method for the cytofluorimetric analysis of mitochondrial membrane potential using the J-aggregate forming lipophilic cation 5, 5', 6, 6'-tetrachloro-1, 1', 3, 3'-tetraethylbenzimidazolcarbocyanine iodide (JC-1). Biochem Biophys Res Commun 197:40-45

de Campos AM, Sanchez A, Alonso MJ (2001) Chitosan nanoparticles: a new vehicle for the improvement of the delivery of drugs to the ocular surface. Application to cyclosporin A. Int J Pharm 224:159-168

Earnshaw WC, Martins LM, Kaufmann SH (1999) Mammalian caspases: structure, activation, substrates, and functions during apoptosis. Annu Rev Biochem 68:383-424

Finsy R (1994) Particle sizing by quasi-elastic light scattering. Advan Colloid Interface Sci 52:79-143

Gao M, Fan S, Goldberg ID et al (2001) Hepatocyte growth factor/ scatter factor blocks the mitochondrial pathway of apoptosis signaling in breast cancer cells. J Biol Chem 276:47257-47265

Genta I, Conti B, Perugini P et al (1997) Bioadhesive microspheres for ophthalmic administration of acyclovir. J Pharm Pharmacol 49:737-742

Green DR, Reed JC (1998) Mitochondria and apoptosis. Science 281:1309-1312

Guo W, Lee T, Sudimack JJ et al (2000) Receptor-specific delivery of liposomes via folate-PEG-chol. J Liposome Res 10:179-195
Janes KA, Fresneau MP, Marazuela A et al (2001) Chitosan nanoparticles as delivery systems for doxorubicin. J Control Release 73:255-267

Ji QX, Zhong DY, Lü R et al (2009) In vitro evaluation of the biomedical properties of chitosan and quaternized chitosan for dental applications. Carbohydr Res 344:1297-1302

Kansara V, Paturi D, Luo S et al (2008) Folic acid transport via high affinity carrier-mediated system in human retinoblastoma cells. Int J Pharm 355:210-219

Kim SL, Jeong HJ, Kim EM et al (2007) Folate receptor targeted imaging using poly (ethylene glycol)-folate: in vitro and in vivo studies. J Korean Med Sci 22:405-411

Kluck RM, Bossy-Wetzel E, Green DR et al (1997) The release of cytochrome $\mathrm{c}$ from mitochondria: a primary site for $\mathrm{Bcl}-2$ regulation of apoptosis. Science 275:1132-1136

Kluza J, Marchetti P, Gallego MA et al (2004) Mitochondrial proliferation during apoptosis induced by anticancer agents: effects of doxorubicin and mitoxantrone on cancer and cardiac cells. Oncogene 23:7018-7030

Koopman G, Reutelingsperger CP, Kuijten GA et al (1994) Annexin $\mathrm{V}$ for flow cytometric detection of phosphatidylserine expression on B cells undergoing apoptosis. Blood 84:1415-1420

Leamon CP, Low PS (2001) Folate-mediated targeting: from diagnostics to drug and gene delivery. Drug Discov Today 6:44-51

Leamon CP, Reddy JA (2004) Folate-targeted chemotherapy. Adv Drug Deliv Rev 56:1127-1141

Lee RJ, Low PS (1995) Folate-mediated tumor cell targeting of liposome-entrapped doxorubicin in vitro. Biochim Biophys Acta 1233:134-144

Liu Y, Li K, Pan J et al (2009) Folic acid conjugated nanoparticles of mixed lipid monolayer shell and biodegradable polymer core for targeted delivery of Docetaxel. Biomaterials 31:330-338

Liu XD, Sun H, Liu GT (2010) 5-Bromotetrandrine enhances the sensitivity of doxorubicin-induced apoptosis in intrinsic resistant human hepatic cancer Bel7402 cells. Cancer Lett 292:24-31

Lu Y, Low PS (2003) Immunotherapy of folate receptor-expressing tumors: review of recent advances and future prospects. J Control Release 91:17-29

Lu Y, Sega E, Leamon CP et al (2004) Folate receptor-targeted immunotherapy of cancer: mechanism and therapeutic potential. Adv Drug Deliv Rev 56:1161-1176

Ly JD, Grubb DR, Lawen A (2003) The mitochondrial membrane potential (deltapsi(m)) in apoptosis; an update. Apoptosis 8:115128

Misra R, Sahoo SK (2010) Intracellular trafficking of nuclear localization signal conjugated nanoparticles for cancer therapy. Eur J Pharm Sci 39:152-163

Mosmann T (1983) Rapid colorimetric assay for cellular growth and survival: application to proliferation and cytotoxicity assays. J Immunol Methods 65:55-63

Mundargi RC, Srirangarajan S, Agnihotri SA et al (2007) Development and evaluation of novel biodegradable microspheres based on poly(d, l-lactide-co-glycolide) and poly(epsilon-caprolactone) for controlled delivery of doxycycline in the treatment of human periodontal pocket: in vitro and in vivo studies. J Control Release 119:59-68

Pan J, Feng SS (2008) Targeted delivery of paclitaxel using folatedecorated poly(lactide)-vitamin E TPGS nanoparticles. Biomaterials 29:2663-2672

Panyam J, Labhasetwar V (2003) Biodegradable nanoparticles for drug and gene delivery to cells and tissue. Adv Drug Deliv Rev 55:329-347

Parveen S, Sahoo SK (2008) Polymeric nanoparticles for cancer therapy. J Drug Target 16:108-123

Parveen S, Mitra M, Krishnakumar S et al (2010) Enhanced antiproliferative activity of carboplatin-loaded chitosan-alginate 
nanoparticles in a retinoblastoma cell line. Acta Biomater 6:3120-3131

Rees M, Smith TW, Chen LB (1991) J-aggregate formation of a carbocyanine as a quantitative fluorescent indicator of membrane potential. Biochemistry 30:4480-4486

Rodriguez-Galindo C, Wilson MW, Chantada G et al (2008) Retinoblastoma: one world, one vision. Pediatrics 122:e763-e770

Rosenholm JM, Meinander A, Peuhu E et al (2009) Targeting of porous hybrid silica nanoparticles to cancer cells. ACS Nano 3:197-206

Ross JF, Chaudhuri PK, Ratnam M (1994) Differential regulation of folate receptor isoforms in normal and malignant tissues in vivo and in established cell lines. Physiologic and clinical implications. Cancer 73:2432-2443

Sahoo SK, Labhasetwar V (2003) Nanotech approaches to drug delivery and imaging. Drug Discov Today 8:1112-1120

Sahoo SK, Labhasetwar V (2005) Enhanced antiproliferative activity of transferrin-conjugated paclitaxel-loaded nanoparticles is mediated via sustained intracellular drug retention. Mol Pharm 2:373-383

Sahoo SK, Parveen S, Panda JJ (2007) The present and future of nanotechnology in human health care. Nanomedicine 3:20-31

Sahoo SK, Dilnawaz F, Krishnakumar S (2008) Nanotechnology in ocular drug delivery. Drug Discov Today 13:144-151

Sahu SK, Mallick SK, Santra S et al (2010) In vitro evaluation of folic acid modified carboxymethyl chitosan nanoparticles loaded with doxorubicin for targeted delivery. J Mater Sci Mater Med 21:1587-1597

Salvioli S, Ardizzoni A, Franceschi C et al (1997) JC-1, but not DiOC6(3) or rhodamine 123, is a reliable fluorescent probe to assess delta psi changes in intact cells: implications for studies on mitochondrial functionality during apoptosis. FEBS Lett 411:7782

Sareen D, van Ginkel PR, Takach JC et al (2006) Mitochondria as the primary target of resveratrol-induced apoptosis in human retinoblastoma cells. Invest Ophthalmol Vis Sci 47:3708-3716

Saul JM, Annapragada A, Natarajan JV et al (2003) Controlled targeting of liposomal doxorubicin via the folate receptor in vitro. J Control Release 92:49-67

Serpe L, Guido M, Canaparo R et al (2006) Intracellular accumulation and cytotoxicity of doxorubicin with different pharmaceutical formulations in human cancer cell lines. J Nanosci Nanotechnol 6:3062-3069

Smith LM, Donaldson SS (1991) Incidence and management of secondary malignancies in patients with retinoblastoma and Ewing's sarcoma. Oncology 5:135-141

Sudimack J, Lee RJ (2000) Targeted drug delivery via the folate receptor. Adv Drug Deliv Rev 41:147-162

Torchilin VP (2005) Recent advances with liposomes as pharmaceutical carriers. Nat Rev Drug Discov 4:145-160

Wan A, Suna Y, Li H (2008) Characterization of folate-graft-chitosan as a scaffold for nitric oxide release. Int $\mathrm{J}$ Biol Macromol 43:415-421

White RJ, Reynolds IJ (1996) Mitochondrial depolarization in glutamate stimulated neurons: an early signal specific to excitotoxin exposure. J Neurosci 16:5688-5697

Yoo HS, Park TG (2004) Folate receptor targeted biodegradable polymeric doxorubicin micelles. J Control Release 96:273-283

Zamzami N, Marchetti P, Castedo M et al (1995) Reduction in mitochondrial potential constitutes an early irreversible step of programmed lymphocyte death in vivo. J Exp Med 181:16611672 